\title{
Article \\ Vulnerability of $\beta$-Thalassemia Heterozygotes to COVID-19: Results from a Cohort Study
}

\author{
Sotirios Sotiriou $^{1}$ (D), Athina A. Samara ${ }^{1, *(D)}$, Konstantinos E. Lachanas ${ }^{2}$, Dimitra Vamvakopoulou ${ }^{3}$, \\ Konstantinos-Odysseas Vamvakopoulos ${ }^{1}$, Nikolaos Vamvakopoulos ${ }^{4}$, Michel B. Janho ${ }^{1}$, \\ Konstantinos Perivoliotis ${ }^{1}$ (D), Christos Donoudis ${ }^{5}$, Alexandros Daponte ${ }^{5}$, Konstantinos I. Gourgoulianis 6 (D) \\ and Stylianos Boutlas ${ }^{6}$ (D)
}

check for updates

Citation: Sotiriou, S.; Samara, A.A.; Lachanas, K.E.; Vamvakopoulou, D.; Vamvakopoulos, K.-O.;

Vamvakopoulos, N.; Janho, M.B.;

Perivoliotis, K.; Donoudis, C.;

Daponte, A.; et al. Vulnerability of $\beta$-Thalassemia Heterozygotes to COVID-19: Results from a Cohort Study. J. Pers. Med. 2022, 12, 352. https: / / doi.org/10.3390/ jpm12030352

Academic Editors: Ioannis Pantazopoulos and Ourania S. Kotsiou

Received: 17 January 2022 Accepted: 24 February 2022 Published: 25 February 2022

Publisher's Note: MDPI stays neutral with regard to jurisdictional claims in published maps and institutional affiliations.

Copyright: (C) 2022 by the authors. Licensee MDPI, Basel, Switzerland. This article is an open access article distributed under the terms and conditions of the Creative Commons Attribution (CC BY) license (https:// creativecommons.org/licenses/by/ $4.0 /)$.
1 Department of Embryology, Faculty of Medicine, School of Health Sciences, University of Thessaly, 41110 Larissa, Greece; sotiriousoti@yahoo.gr (S.S.); kostantinos753@gmail.com (K.-O.V.); micheljanho@live.co.uk (M.B.J.); kperi19@gmail.com (K.P.)

2 Department of Public Health and Social Medicine, Koutlimpanio General Hospital, 41221 Larissa, Greece; klachanas@hotmail.com

3 1st Neonatal Intensive Care Unit, “Agia Sophia” Children's Hospital, 11527 Athens, Greece; gina_dimitra@hotmail.com

4 Department of Biology, Faculty of Medicine, University of Thessaly, 41110 Larissa, Greece; nvamvak@yahoo.com

5 Department of Obstetrics and Gynaecology, Faculty of Medicine, University of Thessaly, 41110 Larissa, Greece; xdonoudis@gmail.com (C.D.); daponte@uth.gr (A.D.)

6 Department of Respiratory Medicine, Faculty of Medicine, University of Thessaly, 41110 Larissa, Greece; kgourg@med.uth.gr (K.I.G.); sboutlas@gmail.com (S.B.)

* Correspondence: at.samara93@gmail.com; Tel.: +30-697-737-9540

\begin{abstract}
Background: The assignment of mortality risk from SARS-CoV-2 virus (COVID-19) to vulnerable patient groups is an important step toward containment of the pandemic. Methods: A total of 760 patients with a positive molecular test for SARS-CoV-2 who were unvaccinated against COVID-19 were recruited between 1 January and 30 June 2021. Patients were grouped by age; sex; and common morbidities, such as atrial fibrillation, chronic respiratory disease, coronary disease, diabetes type II, neoplasia, hypertension and $\beta$-Thalassemia heterozygosity. As a primary endpoint, we assessed mortality risk from COVID-19, and as secondary endpoints, we considered clinical severity and need for Intense Care Unit (ICU) admission. Results: In multivariate analysis, male sex $(p<0.001, \mathrm{OR}=2.59)$, increasing age $(p<0.001, \mathrm{OR}=1.049), \beta$-Thalassemia heterozygosity $(p=0.001$, $\mathrm{OR}=2.41)$ and chronic respiratory disease $(p=0.018, \mathrm{OR}=1.84)$ were identified as risk factors associated with mortality due to COVID-19. Moreover, male sex $(p<0.001, \mathrm{OR}=1.98)$, increasing age $(p<0.001, \mathrm{OR}=1.052)$ and $\beta$-Thalassemia heterozygosity $(p=0.001, \mathrm{OR}=2.59)$ were associated with clinical severity in logistic regression. Regarding ICU admission, the risk factors were identified as male sex $(p=0.002, \mathrm{OR}=1.99)$, chronic respiratory disease $(p=0.007, \mathrm{OR}=2.06)$ and hypertension $(p<0.001, \mathrm{OR}=5.81)$. Conclusions: An increased mortality risk from COVID-19 was observed for older age, male sex, $\beta$-Thalassemia heterozygosity and respiratory disease. Carriers of $\beta$-Thalassemia were identified as more vulnerable for severe clinical symptomatology, but there was no increased possibility for ICU admission. Readjustment of these findings to consider impacts of variant strains prevailing during the latest viral outbreak among vulnerable patient groups may offer timely relief from the pandemic.
\end{abstract}

Keywords: COVID-19; $\beta$-Thalassemia; mortality; critical care; pandemic

\section{Introduction}

Over the last two years, the SARS-CoV-2 virus (COVID-19) pandemic has spread globally, affecting every country worldwide [1]. The identification of common comorbidities that increase the mortality risk by severe acute respiratory syndrome-coronavirus 2 
(COVID-19) is an important first step toward morbidity and mortality risk containment from the pandemic. Early identification, consultation and intervention practices among vulnerable groups could reduce the morbidity rates and mortality risk from COVID-19.

Several risk factors attributing to mortality due to COVID-19, including patients' demographic characteristics and common comorbidities, have been identified since the beginning of the pandemic. More specifically, increasing age and male sex increase the severity and mortality risk [2,3]. Furthermore, common comorbidities, including hypertension, diabetes mellitus and chronic obstructive lung disease, have also been reported as factors associated with an increased mortality in infected patients $[4,5]$.

$\beta$-Thalassemia is the most common inherited single gene disorder in the world, with approximately $1.5 \%$ of the global population being heterozygous for $\beta$-Thalassemia [6]. In a recently published pilot study during the second wave of the pandemic, $\beta$-Thalassemia heterozygotes were identified as a group of patients vulnerable to COVID-19, with an increased mortality risk [7]. These findings have to be updated during the next pandemic waves with novel variants of the virus being dominant.

Herein, to consolidate our pilot observations [7], we analyzed considerably more COVID-19-positive and unvaccinated cases among these vulnerable groups, spanning a longer time period. Mortality risk, clinical severity and need for Intense Care Unit (ICU) admission were assessed as endpoints.

\section{Methods}

\subsection{Settings}

The present retrospective cohort study includes 760 consecutive patients unvaccinated against COVID-19 with a positive SARS-CoV-2 Real-Time Polymerase Chain Reaction (RT-PCR) molecular test. All participants were registered in the emergency department (ER) of the tertiary referral center in central Greece (University Hospital of Larisa), between 1 January and 30 June 2021.

\subsection{Participants and Study Design}

A retrospective analysis was conducted of medical and laboratory records from consecutive patients registered in the ER of a tertiary referral hospital. A database was created based on medical history and laboratory tests of confirmed COVID-19-positive subjects. We examined the mortality risk of vulnerable patient groups with common morbidity symptoms, including $\beta$-Thalassemia heterozygotes. The course of non-hospitalized participants was followed by telephone interviews.

The primary outcome of this study was the association of clinical and demographic variants with mortality due to COVID-19 in infected individuals. COVID-19 infection was the single common official cause of death for our study participants, as registered in hospital archives. Furthermore, clinical severity of symptomatology and need for Intense Care Unit (ICU) admission were considered as secondary endpoints.

Patient demographic characteristics of age; sex; and common morbidities, including atrial fibrillation, chronic respiratory disease, coronary disease, diabetes, neoplasia and hypertension were recorded. In addition, $\beta$-Thalassemia heterozygosity was assessed through laboratory tests and known medical history. We excluded the current smoking-status parameter from patient characteristics being studied, based on preliminary indications of notable absence of statistically significant correlations between smoking and mortality from COVID-19.

\subsection{Ethical Considerations}

Experimental therapeutic protocols were not applicable in this study. All data were analyzed anonymously, using code numbers with respect to the patient's privacy, and collected in the context of routine diagnostic and therapeutic procedures. Nevertheless, the study conformed to the Research and Ethical Committee guidelines of the University Hospital of Larisa. 


\subsection{Sample Estimation}

Considering an estimated prevalence of $8 \%$ in our entire study population, a precision of $\pm 3.5 \%$ and $95 \%$ confidence interval $(\mathrm{CI})$, the minimum sample size required was calculated by a precision analysis, using Epi Info 7 [8]. A minimum study sample was set at 231 patients.

\subsection{Statistical Analysis}

Analysis was carried out by using SPSS version 26.0 (IBM, Chicago, IL, USA). Categorical variables are described by using frequency and relative frequency. Continuous variables are described with means and standard deviation. Analysis of continuous variables was conducted by using the Mann-Whitney U test and Kruskal-Wallis test, since the assumption of normal distribution was violated. Data were checked for deviation from normal distribution, using the Shapiro-Wilk normality test. Categorical data were analyzed with the use of Chi-square test or Fisher's exact test. Multivariate analysis was performed in the form of binary logistic regression. For all the analyses, a 5\% significance level was set.

\section{Results}

A total of 760 patients were included in the study, of which 448 (58.9\%) were male and $312(41.1 \%)$ female, with a mean age of $62.21( \pm 16.42)$ years, ranging from 20 to 93 . A total of $448(58,9 \%)$ patients were male and $312(41.1 \%)$ female. Overall, 189 study participants died, resulting in a mortality rate of $24.86 \%$.

Regarding mortality, in univariate analysis, male sex $(p<0.001, \mathrm{OR}=2.44)$, increased age $(p<0.001)$, atrial fibrillation $(p<0.001, \mathrm{OR}=2.44)$, chronic respiratory disease $(p<0.001$, $\mathrm{OR}=2.71)$, coronary disease $(p<0.001, \mathrm{OR}=2.11)$, hypertension $(p<0.001, \mathrm{OR}=2.77)$ and $\beta$-Thalassemia heterozygosity $(p<0.001, \mathrm{OR}=2.26)$ were associated with increased mortality due to COVID-19 (Table 1).

Table 1. Assessing mortality risk of study groups from COVID-19 by univariate and multivariate statistical analysis.

\begin{tabular}{|c|c|c|c|c|c|c|c|}
\hline & & \multirow{2}{*}{$\begin{array}{c}\begin{array}{l}\text { Outcome: } \\
\text { Mortality }\end{array} \\
\text { Yes (\%) }\end{array}$} & \multicolumn{3}{|c|}{ Univariate } & \multicolumn{2}{|c|}{$\begin{array}{c}\text { Multivariate } \\
\text { Binary Logistic } \\
\text { Regression }\end{array}$} \\
\hline & & & Sig. & OR with $95 \% \mathrm{CI}$ & RR with $95 \%$ CI & Sig. & aOR with $95 \% \mathrm{CI}$ \\
\hline $\operatorname{Sex}(M / F)$ & $\begin{array}{l}\text { M: } \\
\text { F: }\end{array}$ & $\begin{array}{l}140(31.3) \\
49(15.7)\end{array}$ & $<0.001(\mathrm{C})$ & $2.44(1.69-3.51)$ & $1.99(1.49-2.66)$ & $<0.001(\mathrm{C})$ & $2.59(1.73-3.90)$ \\
\hline $\begin{array}{l}\text { Age (median, } \\
\text { IQR) }\end{array}$ & & $\begin{array}{l}\text { Dead: } 73(16) \\
\text { Alive: } 62(23)\end{array}$ & $<0.001(\mathrm{M}-\mathrm{W})$ & - & - & $<0.001(\mathrm{C})$ & 1.049 (1.031-1.066) \\
\hline $\begin{array}{l}\beta \text {-Thalassemia } \\
\text { heterozygosity }\end{array}$ & $\begin{array}{l}\text { Yes: } \\
\text { No: }\end{array}$ & $\begin{array}{c}53(38.7) \\
136(21.8)\end{array}$ & $<0.001(\mathrm{C})$ & $2.26(1.53-3.35)$ & $1.77(1.37-2.29)$ & 0.001 & $2.41(1.55-3.74)$ \\
\hline $\begin{array}{l}\text { Chronic } \\
\text { respiratory } \\
\text { disease }\end{array}$ & $\begin{array}{l}\text { Yes: } \\
\text { No: }\end{array}$ & $\begin{array}{c}41(43.6) \\
148(22.2)\end{array}$ & $<0.001(\mathrm{C})$ & $2.71(1.73-4.23)$ & $1.96(1.50-2.57)$ & 0.018 & $1.84(1.11-3.05)$ \\
\hline Atrial fibrillation & $\begin{array}{l}\text { Yes: } \\
\text { No: }\end{array}$ & $\begin{array}{r}84(37.0) \\
103(19.4)\end{array}$ & $<0.001(\mathrm{C})$ & $2.44(1.73-3.45)$ & $1.91(1.50-2.43)$ & 0.058 & $1.50(0.99-2.28)$ \\
\hline Hypertension & $\begin{array}{l}\text { Yes: } \\
\text { No: }\end{array}$ & $\begin{array}{l}138(32.9) \\
51(15.0)\end{array}$ & $<0.001(\mathrm{C})$ & $2.77(1.93-3.98)$ & $2.19(1.64-2.92)$ & 0.243 & $1.31(0.83-2.04)$ \\
\hline Coronary disease & $\begin{array}{l}\text { Yes: } \\
\text { No: }\end{array}$ & $\begin{array}{c}53(37.3) \\
136(22.0)\end{array}$ & $<0.001(\mathrm{C})$ & $2.11(1.43-3.12)$ & $1.70(1.31-2.20)$ & 0.617 & $0.89(0.55-1.42)$ \\
\hline $\begin{array}{l}\text { Diabetes mellitus } \\
\text { type II }\end{array}$ & $\begin{array}{l}\text { Yes: } \\
\text { No: }\end{array}$ & $\begin{array}{r}48(30.8) \\
141(23.3)\end{array}$ & $0.056(\mathrm{C})$ & $1.46(0.99-2.15)$ & $1.32(1.00-1.74)$ & 0.439 & $0.84(0.54-1.30)$ \\
\hline Neoplasia & $\begin{array}{l}\text { Yes: } \\
\text { No: }\end{array}$ & $\begin{array}{r}27(31.8) \\
162(24.1)\end{array}$ & $0.122(\mathrm{C})$ & $1.47(0.90-2.40)$ & $1.32(0.94-1.85)$ & 0.653 & $0.88(0.52-1.51)$ \\
\hline
\end{tabular}

C, Chi-square test; F, Fisher's exact test; M-W, Mann-Whitney U test.

In logistic regression analysis, male patients were 2.6 times more likely to die than female patients $(p<0.001, \mathrm{OR}=2.59)$. Furthermore, older participants were more likely to die from COVID-19; moreover, every year of age increased the possibility to die by $4.9 \%$ $(p<0.001, \mathrm{OR}=1.049)$. Patients with underlying chronic respiratory disease had a 1.8-times increased mortality possibility than patients without respiratory disease history $(p=0.018$, 
$\mathrm{OR}=1.84)$. Interestingly, $\beta$-Thalassemia heterozygotes had a 2.4-times increased possibility of mortality compared to patients without the trait $(p<0.001, \mathrm{OR}=2.41)$ (Figure 1$)$. There was no statistically significant association between COVID-19 attributed mortality and other comorbidities, such as atrial fibrillation $(p=0.058)$, hypertension $(p=0.243)$, coronary disease $(p=0.617)$, diabetes type II $(p=0.439)$ and neoplasia $(p=0.653)$ (Table 1$)$.

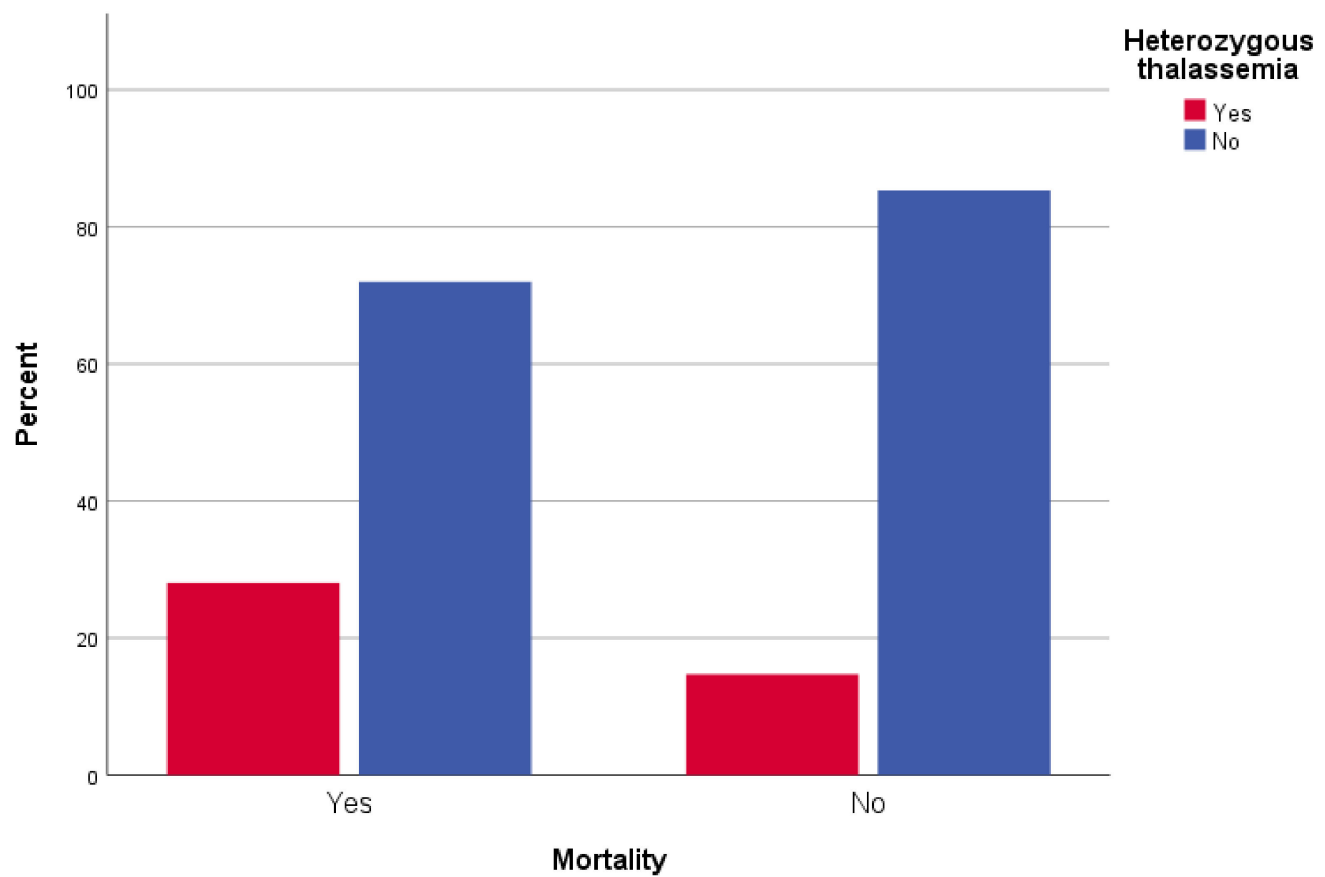

Figure 1. Mortality of $\beta$-Thalassemia heterozygotes from COVID-19: distribution of SARS-CoV-2 infected $\beta$-Thalassemia trait carriers (red box) among study participants who died (Yes), or survived (No) from COVID-19, relative to non-carriers (blue box).

Regarding severity of clinical symptoms, in univariate analysis, male sex $(p<0.001)$, increased age $(p<0.001)$, atrial fibrillation $(p<0.001)$, chronic respiratory disease $(p<0.001)$, coronary disease $(p<0.001)$, hypertension $(p<0.001)$ and $\beta$-Thalassemia heterozygosity $(p<0.001)$ were associated with increased severity of clinical symptoms attributed to COVID-19 (Table 2). Moreover, in logistic regression, there was almost double the possibility of severe clinical disease for male patients than female ones $(p<0.001, \mathrm{OR}=1.98)$. Older participants were more likely to have symptoms with increased severity $(p<0.001$, $\mathrm{OR}=1.052$ ), with every year of age increasing the possibility of severe disease by $5.2 \%$. $\beta$-Thalassemia heterozygosity was also identified as an independent risk factor for severe clinical symptoms of COVID-19 ( $p<0.001, \mathrm{OR}=2.59)$ (Figure 2$)$.

When assessing ICU admission, in univariate analysis, male sex $(p=0.001)$, increased age $(p=0.005)$, chronic respiratory disease $(p<0.001)$, coronary disease $(p<0.001)$ and hypertension $(p<0.001)$ were associated with the need for ICU admission. In logistic regression, male patients had double the possibility for ICU stay than female ones $(p=0.002$, $\mathrm{OR}=1.99$ ). Furthermore, chronic respiratory disease and hypertension were identified as independent risk factors for ICU admission due to COVID-19 ( $p=0.007$, OR = 2.06 and $p<0.001, \mathrm{OR}=5.81$ respectively), with patients with hypertension being 5.8 times more possible to need ICU. 
Table 2. Assessing clinical severity of COVID-19 by univariate and multivariate statistical analysis.

\begin{tabular}{|c|c|c|c|c|c|c|}
\hline & \multicolumn{3}{|c|}{ Outcome: Severity } & \multirow{2}{*}{$\begin{array}{c}\text { Univariate } \\
\text { Sig. }\end{array}$} & \multicolumn{2}{|c|}{$\begin{array}{c}\text { Multivariate } \\
\text { Ordinal Logistic Regression }\end{array}$} \\
\hline & Asymptomatic-Mild (\%) & Moderate (\%) & Severe-Critical (\%) & & Sig. & aOR with $95 \% \mathrm{CI}$ \\
\hline Sex (Male) & $94(49.5)$ & $210(56.3)$ & $144(73.1)$ & $<0.001(\mathrm{C})$ & $<0.001$ & $1.98(1.47-2.66)$ \\
\hline Age (median, IQR) & $52(32)$ & $65(18)$ & $72(16)$ & $<0.001(\mathrm{~K}-\mathrm{W})$ & $<0.001$ & $1.052(1.040-1.064)$ \\
\hline Atrial Fibrillation & $51(26.8)$ & $93(24.9)$ & $83(42.6)$ & $<0.001(\mathrm{C})$ & 0.373 & $0.85(0.60-1.21)$ \\
\hline $\begin{array}{l}\text { Chronic respiratory } \\
\text { disease }\end{array}$ & $15(7.9)$ & $38(10.2)$ & $41(20.8)$ & $<0.001(\mathrm{C})$ & 0.098 & $1.45(0.93-2.26)$ \\
\hline Coronary disease & $20(10.5)$ & $69(18.5)$ & $53(26.9)$ & $<0.001(\mathrm{C})$ & 0.634 & $1.10(0.73-1.67)$ \\
\hline $\begin{array}{l}\text { Diabetes mellitus } \\
\text { Type II }\end{array}$ & $29(15.3)$ & $79(21.2)$ & $48(24.4)$ & $0.078(\mathrm{C})$ & 0.331 & $0.83(0.58-1.20)$ \\
\hline Neoplasia & $20(10.5)$ & $35(9.4)$ & $30(15.2)$ & $0.108(C)$ & 0.173 & $0.73(0.47-1.15)$ \\
\hline Hypertension & $69(36.3)$ & $204(54.7)$ & $147(74.6)$ & $<0.001(\mathrm{C})$ & 0.104 & $1.34(0.94-1.91)$ \\
\hline $\begin{array}{l}\beta \text {-Thalassemia } \\
\text { heterozygosity }\end{array}$ & $15(7.9)$ & $66(17.7)$ & $56(28.4)$ & $<0.001(\mathrm{C})$ & $<0.001$ & $2.59(1.78-3.77)$ \\
\hline
\end{tabular}

C, Chi-square test; K-W, Kruskal-Wallis Test.

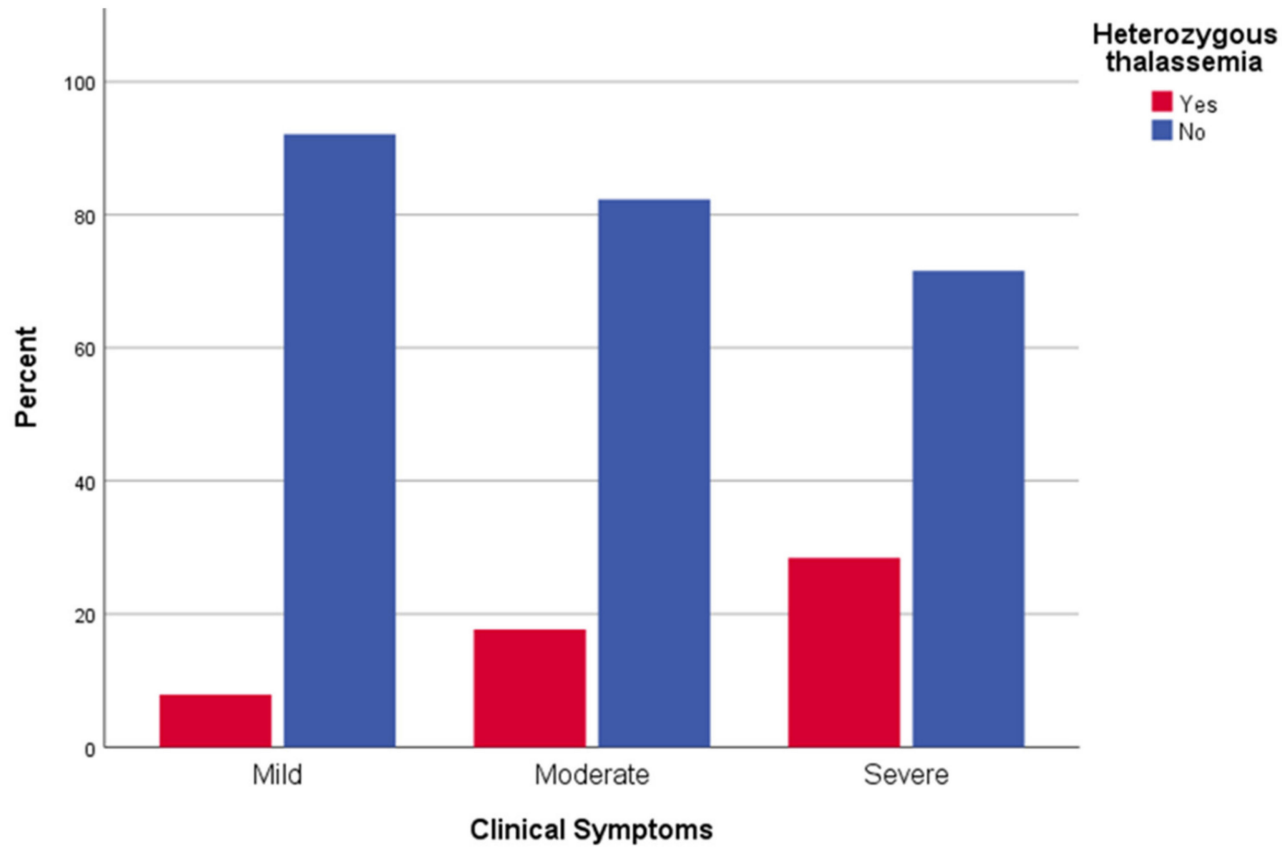

Figure 2. Clinical symptoms of COVID-19 in $\beta$-Thalassemia heterozygotes patients and control: distribution of clinical symptoms of SARS-CoV-2-infected $\beta$-Thalassemia trait carriers (red box) and non-carriers (blue box).

\section{Discussion}

In the present study, we assessed the role of common comorbidities as independent risk factors for COVID-19 attributed mortality among 760 unvaccinated patients against SARS-CoV-2 during the first half of 2021. The current findings support earlier observations of strong statistical association between mortality due to COVID-19 and male sex, increased age, chronic respiratory disease and $\beta$-Thalassemia heterozygosity [3,5-8]. Patients with underlying chronic respiratory disease were included in the high-mortality-risk group of patients from the beginning of the pandemic [9].

$\beta$-Thalassemias are a group of hereditary autosomal recessive anemias caused by either reduced or complete absence of production of $\beta$-globin chains of the hemoglobin tetramer [10]. Data regarding potential effects of associated comorbidities in thalassemic patients with COVID-19 are limited. Recent studies reported that patients with $\beta$-Thalassemia have a chronic condition which may contribute to an increase in susceptibility to SARSCoV-2 infection [11,12]. The underlying disease is associated with several comorbidities 
and complications of chronic transfusions, including heart failure, pulmonary hypertension, hypogonadism and diabetes, that may attribute to the susceptibility of this group of patients to COVID-19 infection [11].

In this context, it is necessary to investigate the potential role of the $\beta$-Thalassemia trait as a risk factor for morbidity and mortality by COVID-19. The compromised nature of response to stress that is inherent to asymptomatic or mildly anemic $\beta$-Thalassemia heterozygotes facilitates collective induction of innate immune receptor CD45, Toll-like receptor 4 and CD32 expression; reduces ability to produce oxidative bursts; and elevates membrane lipid peroxidation [13]. Borderline resistance of $\beta$-Thalassemia trait carriers to stress may explain the low threshold of COVID-19 symptoms required to begin treatment that appear with considerable time lag, require longer periods of hospitalization and ICU care and result in over twice the possibility of mortality due to COVID-19.

The vascular nature of COVID-19 symptoms leads to mortality from cardiovascular (CVS) failure [14], rendering CVS control a primary target during the pandemic. CVS control is exerted through classical renin-angiotensin system (RAS)-inducing vasoconstriction via renin processed angiotensin II (ATII) vasoconstrictors, and counter-balancing nonclassical RAS-inducing vasodilation via ACE2 conversion of ATII or processing of ATI to AT 1-7 vasodilators [15,16]. SARS-CoV-2 inhibits ACE2 expression and deranges CVS homeostasis [16]. Current COVID-19 treatment strategies aim to suppress SARS-CoV-2 main protease activity, required to release active viral protein products [17] and induce ACE2 expression [16]. Thus, CVS control of COVID-19 positive vulnerable patient groups by statins, merits thorough consideration as a potential first-line treatment option.

Updated data of patients with adaptive evolutionary viral alterations may improve the representability of data collection and enhance the reliability of associated clinical findings. Future studies on COVID-19 mortality risk should address pregnancy and highrisk pregnancy, particularly for women with genotypic variations associated with early onset preeclampsia, such as variant TLR-4 alleles [18], and mutant angiotensin type I and type II receptor combination genotypes [19].

This new addition may have not only statistical explanations (more participants analyzed), but mainly biological explanations (longer time period of data collection). A possible biological explanation for the observed mortality boost of this new subgroup may rely on the enriched blend of viral variants that prevailed during the first half of 2021, rather than during its narrower last quarter of 2020 previously examined [3]. According to this explanation, the reliability of clinical observations related to mortality impact from COVID-19 depends on timing of participant data collection during the course of the pandemic.

The present study identified independent risk factors associated with mortality due to COVID-19. The most noteworthy association is confirmation of the susceptibility of individuals heterozygous for $\beta$-Thalassemia to COVID-19. However, prior to the appraisal of these results, several limitations should be considered. Data were collected retrospectively, depending on the availability and accuracy of data records, and information bias may have occurred. Furthermore, data were collected from a single tertiary hospital, and the generalization of our findings is limited.

Analogous studies on the distribution of mortality risk from COVID-19 among heterozygotes of less frequent abnormal hemoglobins [20] may help elucidate key mortality factors of this vulnerable asymptomatic group and are worth pursuing on both clinical and academic grounds.

\section{Conclusions}

We conclude that COVID-19 mortality is affected primarily by male sex, aging, $\beta$ Thalassemia trait and chronic respiratory disease/asthma, followed by atrial fibrillation, hypertension, coronary disease, diabetes and neoplasia. Timely accounts of these observations with vaccination against SARS-CoV-2 will assess the effect of vaccination status on 
mortality risk and facilitate early identification, consultation and treatment of COVID-19susceptible cases for optimal pandemic control.

Author Contributions: Conceptualization, S.S., S.B. and A.A.S.; methodology, K.E.L.; formal analysis, K.P.; investigation, M.B.J., D.V., K.-O.V. and C.D.; writing—original draft preparation, S.S. and A.A.S.; writing-review and editing, K.I.G. and A.D.; supervision, S.B., K.I.G., N.V. and A.D. All authors have read and agreed to the published version of the manuscript.

Funding: This research received no external funding.

Institutional Review Board Statement: The study was conducted according to the guidelines of the Declaration of Helsinki, and approved by the Institutional Review Board of University Hospital of Larissa.

Data Availability Statement: Data are available upon reasoning request.

Acknowledgments: Special thanks to Lemonia Anagnostopoulos for language editing.

Conflicts of Interest: The authors declare that there is no conflict of interest.

\section{References}

1. World Health Organization. WHO Coronavirus (COVID-19) Dashboard. Available online: https://covid19.who.int/ (accessed on 8 January 2022).

2. Ramírez-Soto, M.C.; Arroyo-Hernández, H.; Ortega-Cáceres, G. Sex differences in the incidence, mortality, and fatality of COVID-19 in Peru. PLoS ONE 2021, 16, e0253193. [CrossRef] [PubMed]

3. Shakor, J.K.; Isa, R.A.; Babakir-Mina, M.; Ali, S.I.; Hama-Soor, T.A.; Abdulla, J.E. Health related factors contributing to COVID-19 fatality rates in various communities across the world. J. Infect. Dev. Ctries 2021, 15, 1263-1272. [CrossRef] [PubMed]

4. Seong, G.M.; Baek, A.R.; Baek, M.S.; Kim, W.Y.; Kim, J.H.; Lee, B.Y.; Na, Y.S.; Lee, S.I. Comparison of Clinical Characteristics and Outcomes of Younger and Elderly Patients with Severe COVID-19 in Korea: A Retrospective Multicenter Study. J. Pers. Med. 2021, 11, 1258. [CrossRef] [PubMed]

5. Gao, Y.D.; Ding, M.; Dong, X.; Zhang, J.J.; Kursat Azkur, A.; Azkur, D.; Gan, H.; Sun, Y.L.; Fu, W.; Li, W.; et al. Risk factors for severe and critically ill COVID-19 patients: A review. Allergy 2021, 76, 428-455. [CrossRef] [PubMed]

6. Whetheral, D.J. The thalassemias. In Williams Hematology, 5th ed.; Beutler, E., Lichtman, M.A., Coller, B.S., Kipps, T.J., Eds.; McGraw-Hill: New York, NY, USA, 1995.

7. Sotiriou, S.; Samara, A.A.; Vamvakopoulou, D.; Vamvakopoulos, K.-O.; Sidiropoulos, A.; Vamvakopoulos, N.; Janho, M.B.; Gourgoulianis, K.I.; Boutlas, S. Susceptibility of $\beta$-thalassemia heterozygotes to COVID-19. J. Clin. Med. 2021, 10, 3645. [CrossRef] [PubMed]

8. Dean, A.; Arner, T.; Sunki, G.; Friedman, R.; Lantinga, M.; Sangam, S.; Zubieta, J.C.; Sullivan, K.M.; Brendel, K.A.; Gao, Z.; et al. Epi Info. (TM), a Database and Statistics Program for Public Health Professionals, 7.2.3.1 ed.; CDC: Atlanta, GA, USA, 2011.

9. Cho, K.H.; Kim, S.W.; Park, J.W.; Do, J.Y.; Kang, S.H. Effect of Sex on Clinical Outcomes in Patients with Coronavirus Disease: A Population-Based Study. J. Clin. Med. 2020, 10, 38. [CrossRef] [PubMed]

10. O'Brien, J.; Du, K.Y.; Peng, C. Incidence, clinical features, and outcomes of COVID-19 in Canada: Impact of sex and age. J. Ovarian Res. 2020, 13, 137. [CrossRef] [PubMed]

11. Wang, M.; Jiang, N.; Li, C.; Wang, J.; Yang, H.; Liu, L.; Tan, X.; Chen, Z.; Gong, Y.; Yin, X.; et al. Sex-Disaggregated Data on Clinical Characteristics and Outcomes of Hospitalized Patients With COVID-19: A Retrospective Study. Front. Cell. Infect. Microbiol. 2021, 11, 680422. [CrossRef] [PubMed]

12. Peckham, H.; de Gruijter, N.M.; Raine, C.; Radziszewska, A.; Ciurtin, C.; Wedderburn, L.R.; Rosser, E.C.; Webb, K.; Deakin, C.T. Male sex identified by global COVID-19 meta-analysis as a risk factor for death and ITU admission. Nat. Commun. 2020, 11, 6317. [CrossRef] [PubMed]

13. Seltzer, S. Linking ACE2 and angiotensin II to pulmonary immunovascular dysregulation in SARS-CoV-2 infection. Int. J. Infect. Dis. 2020, 101, 42-45. [CrossRef] [PubMed]

14. Galanello, R.; Origa, R. Beta-thalassemia. Orphanet J. Rare Dis. 2010, 5, 11. [CrossRef] [PubMed]

15. Karimi, M.; Haghpanah, S.; Zarei, T.; Azarkeivan, A.; Shirkavand, A.; Matin, S.; Tavakoli, M.A.; Zahedi, Z.; De Sanctis, V. Prevalence and severity of Coronavirus disease 2019 (COVID-19) in Transfusion Dependent and Non-Transfusion Dependent $\beta$-thalassemia patients and effects of associated comorbidities: An Iranian nationwide study. Acta Biomed. 2020, 91, e2020007. [CrossRef] [PubMed]

16. Karimi, M.; Haghpanah, S.; Azarkeivan, A.; Zahedi, Z.; Zarei, T.; Akhavan Tavakoli, M.; Bazrafshan, A.; Shirkavand, A.; De Sanctis, V. Prevalence and mortality in $\beta$-thalassaemias due to outbreak of novel coronavirus disease (COVID-19): The nationwide Iranian experience. Br. J. Haematol. 2020, 190, e137-e140. [CrossRef] [PubMed]

17. Ondei, L.D.S.; Estevão, I.D.F.; Rocha, M.I.P.; Percário, S.; Souza, D.R.S.; Pinhel, M.A.D.S.; Bonini-Domingos, C.R. Oxidative stress and antioxidant status in beta-thalassemia heterozygotes. Rev. Bras. Hematol. Hemoter. 2013, 35, 409-413. [CrossRef] [PubMed] 
18. Chung, M.K.; Zidar, D.A.; Bristow, M.R.; Cameron, S.J.; Chan, T.; Harding, C.V., III; Kwon, D.H.; Singh, T.; Tilton, J.C.; Tsai, E.J.; et al. COVID-19 and Cardiovascular Disease. Circ. Res. 2021, 128, 1214-1236. [CrossRef] [PubMed]

19. Li, X.C.; Zhang, J.; Zhuo, J.L. The vasoprotective axes of the renin-angiotensin system: Physiological relevance and therapeutic implications in cardiovascular, hypertensive and kidney diseases. Pharmacol. Res. 2017, 125, 21-38. [CrossRef] [PubMed]

20. Aleksova, A.; Gagno, G.; Sinagra, G.; Beltrami, A.; Janjusevic, M.; Ippolito, G.; Zumla, A.; Fluca, A.; Ferro, F. Effects of SARS-CoV-2 on Cardiovascular System: The Dual Role of Angiotensin-Converting Enzyme 2 (ACE2) as the Virus Receptor and Homeostasis Regulator-Review. Int. J. Mol. Sci. 2021, 22, 4526. [CrossRef] [PubMed] 